\title{
Assessment of Climate Change over South America under RCP 4.5 and 8.5 Downscaling Scenarios
}

\author{
Sin Chan Chou1, André Lyra1, Caroline Mourão', Claudine Dereczynski², Isabel Pilotto1, \\ Jorge Gomes ${ }^{1}$, Josiane Bustamante ${ }^{1}$, Priscila Tavares ${ }^{1}$, Adan Silva1, Daniela Rodrigues ${ }^{1}$, \\ Diego Campos', Diego Chagas', Gustavo Sueiro', Gracielle Siqueira', José Marengo ${ }^{3}$ \\ ${ }^{1}$ National Institute for Space Research, Cachoeira Paulista, Brazil \\ ${ }^{2}$ Department of Meteorology, Federal University of Rio de Janeiro, Rio de Janeiro, Brazil \\ ${ }^{3}$ National Center for Natural Disaster Monitoring and Warning, São José dos Campos, Brazil \\ Email: chou.sinchan@cptec.inpe.br
}

Received 4 October 2014; revised 2 November 2014; accepted 27 November 2014

Copyright (C) 2014 by authors and Scientific Research Publishing Inc.

This work is licensed under the Creative Commons Attribution International License (CC BY). http://creativecommons.org/licenses/by/4.0/

\section{(c) (i) Open Access}

\begin{abstract}
Four sets of downscaling simulations based on the Eta Regional Climate Model forced by two global climate models, the HadGEM2-ES and the MIROC5, and two RCP scenarios-8.5 and 4.5, have been carried out. The objective of this work is to assess the climate change over South America based on the Eta simulations. The future changes are shown in timeslices of 30 years: 2011-2040; 2041-2070 and 2071-2100. The climate change response of the Eta simulations nested in HadGEM2-ES is larger than the Eta nested in MIROC5. Major warming area is located in the central part of Brazil. In austral summer, the reduction of precipitation in the central part and the increase in the southeastern part of the continent are common changes in these simulations, while the EtaHadGEM2-ES intensifies the decrease of precipitation in central Brazil, the Eta-MIROC5 expands the area of increase of precipitation in southern Brazil toward the end of the century. In austral winter, precipitation decrease is found in the northern part of South America and in most of Central America, whereas the reduction in southeastern South America is limited to near coastal region. The time series of temperatures show that warming trends are larger in the Eta-HadGEM2-ES than in the Eta-MIROC5 simulations. Heavier precipitation rates are projected in the Central-South of Brazil toward the end of the century. Increase in the length of consecutive dry days (CDD) in Northeast of Brazil and the decrease of consecutive wet days (CWD) in the Amazon region are common features in these simulations.
\end{abstract}

\section{Keywords}

South America, Climate Downscaling, Climate Change Assessment, Climatic Extreme Indicators, 


\section{Eta Model}

\section{Introduction}

Assessment of the impacts of climate change in various socio-economic sectors is an activity necessary for planning at long range. The impacts and vulnerability are local scale issues that require more detailed climate information. Global Climate Models (GCMs) are the major tool to provide information of climate change under different greenhouse gases emission scenarios. However, the grid sizes of these models are about $200-100 \mathrm{~km}$. Local features, such as topography, river basins, and coastlines may not be sufficiently captured in the simulations carried out by those GCMs. The regional climate models (RCMs) play the important role of downscaling the global climate simulations to smaller grid sizes in the area of interest where the impact studies can be carried out. The RCMs simulations with grid sizes of about a few tens of kilometers are a compromise between resolution and the long-term integration.

In South America, some RCM runs have adopted the Special Report on Emission Scenarios-SRES [1] [2] emission scenarios to study the impacts of climate change over South America. Reference [3] compared the climatic changes in A2 and B2, a pessimist and an optimistic scenario, using RegCM3. Reference [4] assessed the future climate under the A1B scenario using the Eta model as the RCM [5] [6], driven by four members of the HadCM3 simulations. These works share the common result of reduction of precipitation in the tropical areas of the continent, and increase of precipitation in the area known as Southeast South America (SESA), that extends from southern Brazil, Uruguay, Paraguay up to northern Argentina. The differences of the climatic changes in different scenarios were mostly differences in magnitude of the changes, with little variation on the location of the changes.

The Brazilian Second National Communication to the United Nations Framework Convention on Climate Change (UNFCCC) was mostly based on the simulations using the SRES scenarios based on the IPCC $4^{\text {th }}$ Assessment Report (AR4). The recently issued IPCC $5^{\text {th }}$ Assessment Report (AR5) is based on the Representative Concentration Pathway scenarios, RCP 8.5, 6, 4.5, and $2.6 \mathrm{Wm}^{-2}$ radiative forcing scenarios, which correspond to the range from pessimist to the optimistic emission scenarios. The GCMs used in the AR5, in general, have shown improvement over the previous GCMs used in AR4, in particular the simulations of precipitation over the tropical areas [7].

In support of the Brazilian Third National Communication to the UNFCCC and of various studies of strategic themes, four sets of downscaling simulations based on the Eta RCM forced by two RCP scenarios-RCP 8.5 and RCP 4.5, and two GCMs, the HadGEM2-ES and the MIROC5, have been carried out. Evaluations of the nested regional simulations of the present climate against observations have been performed in a companion paper [8].

The objective of this work is to assess the climate change over South America based on the Eta model simulations nested in two GCMs and two RCPs scenarios. The assessment is carried out in terms of the annual cycle, frequency distribution, and some climatic extreme indicators.

\section{Data and Methodology}

\subsection{The Scenarios}

In the AR4 [9], the emission scenarios were built based on the storylines that were grouped into a more economically concerned development or a more environmental and sustainable development, and into a more globalized world or a more regionally developing world. The economic models followed various lines of economic development. In the AR5 [10], the scenarios are based on total anthropogenic radiative forcings at the end of the $21^{\text {st }}$ century. Economic models can take different paths to reach four different radiative forcings that are equivalent to different concentration paths of the greenhouse gases, the so-called RCPs. The four different scenarios are labeled as: RCP 8.5, RCP 6.0, RCP 4.5 and RCP 2.6, which correspond to radiative forcings of $8.5 \mathrm{Wm}^{-2}, 6.0$ $\mathrm{Wm}^{-2}, 4.5 \mathrm{Wm}^{-2}$, and $2.6 \mathrm{Wm}^{-2}$, respectively. The first RCP is the most pessimistic and results in a global average warming at the end of the $21^{\text {st }}$ century of about $4^{\circ} \mathrm{C}$, whereas the last RCP is the most optimistic and corresponds to a global warming of about $1^{\circ} \mathrm{C}$. The radiative forcing in RCP 8.5 corresponds approximately to A2 scenario in AR4, it grows almost linearly during the $21^{\text {st }}$ century, but with higher radiative forcing values. On the other hand, the RCP 4.5 corresponds approximately to B1 scenario in AR4, the radiative forcing increases almost 
linearly up to about the year 2060 and then slows down the increase rate until the end of the century where it stabilizes. In this work, the results are shown for RCP 8.5 and RCP 4.5 scenarios.

\subsection{The Models}

Two GCMs are adopted for downscaling: the HadGEM2-ES and MIROC5. The HadGEM2-ES is a global climate model of earth system category developed by the Hadley Centre [11] [12]. The resolution is about 1.875 degrees in longitude and 1.275 degrees in latitude, and 38 levels in the atmosphere. It has dynamic vegetation scheme with carbon cycle representation. The MIROC5 [13] is a Japanese cooperatively developed coupled ocean-atmosphere model of resolution of about $150 \mathrm{~km}$ in horizontal and 40 levels in vertical. A list of major characteristics and references of these two models can be found in the Table 9. A.1 in [7].

Regional Eta model has been adapted to run for long-term integrations [4]-[6]. The dynamics of the model is developed in the eta vertical coordinate [14], which is more suitable to operate in regions of steep orography such as the Andes Cordillera in South America and Central America. Characteristics of the models are based on the upgraded version described in [15] and in a companion paper [8]. The model updates the equivalent $\mathrm{CO}_{2}$ concentration at every 3 years. Vegetation greenness varies monthly, but same type of vegetation is kept during the integration period. The model does not have ocean dynamics. The sea surface temperature is taken from each global model output and it is updated daily in the Regional Eta model. Initial soil moisture and soil temperature come from the respective GCMs. Update of soil conditions follows the NOAH land surface scheme [16]. Lateral boundaries are updated with global model state variables at every 6-hour interval. The regional model resolution is approximately $20 \mathrm{~km}$ in the horizontal and 38 layers in the vertical. The top of the model is at $25 \mathrm{hPa}$. Model domain encompasses most of South America and Central America and part of adjacent oceans (Figure 1).

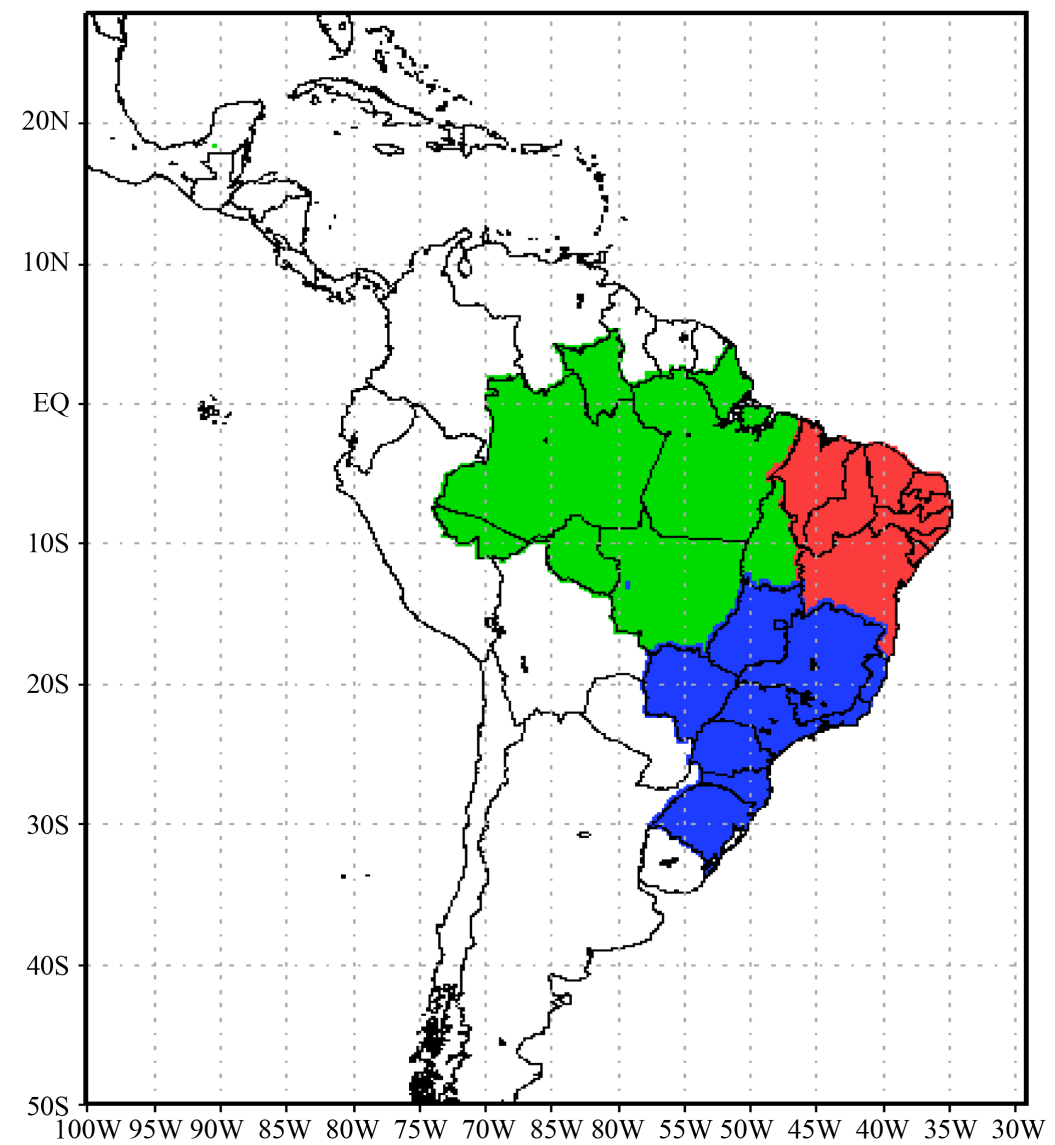

Figure 1. Model domain. Three major Brazilian regions are highlighted in the results: North (NO-green), Northeast (NE-red), and Central-South (CS-blue) Brazil. 


\section{Results}

Results are shown in future timeslices of 30 years: 2011-2040, 2041-2070 and 2071-2100. Climate changes are assessed with respect to the baseline period, 1961-1990, considered as the present climate. The assessment is primarily based on temperature and precipitation displayed in seasonal mean changes, annual cycle, time series, frequency distribution and climatic extreme indicators. Discussions for the three major Brazilian regions, North (NO), Northeast (NE), and the Central-South (CS) regions (Figure 1) are highlighted in the results. The downscaling simulations are referred to as Eta-HadGEM when the Eta model is driven by HadGEM2-ES, and EtaMIROC5 when driven by MIROC5.

\subsection{Seasonal Mean Changes}

- 2-m temperature

The mean change of 2-m temperature projected by the Eta-HadGEM and Eta-MIROC5 simulations, for the three timeslices: 2011-2040, 2041-2070 and 2071-2100, and for the two emission scenarios: RCP 4.5 and RCP 8.5 are shown in Figure 2 for austral summer, December-January-February (DJF), and in Figure 3 for austral winter, June-July-August (JJA). Composites of the upper and lower ranges of the temperature changes among the four projections are included in the two rightmost columns. The Eta-HadGEM is clearly more sensitive to the increase of greenhouse gases in comparison to the Eta-MIROC5 simulations. In austral summer, while, in the near term, 2011-2040, the Eta-MIROC5 reaches warming of about $1.5^{\circ} \mathrm{C}$ and $2^{\circ} \mathrm{C}$, the Eta-HadGEM simulations warming reaches about $4^{\circ} \mathrm{C}$. The most sensitive area, where major warming occurs, is located in Central and Southeast Brazil, a highly dense populated area. As the equivalent $\mathrm{CO}_{2}$ concentration increases through the years, this major warming area expands northward and reaches the tropical areas such as NO region. In the last timeslice, 2071-2100, maxima of temperature changes have reached warming of about $9^{\circ} \mathrm{C}$ in Eta-HadGEM scenario RCP 8.5, taking most of the South America continent, and includes Central America. Largest warming area occurs over the continent. In austral winter, the temperature changes are of similar magnitude, but slightly larger than in summer. Some differences of changes between the two seasons can be noticed, such as around northern Argentina and Paraguay where the minimum warming is projected over the continent in JJA. This is a preferential area of frontogenesis during wintertime [17]. This warming in northern Argentina favours more intense frontogenesis development.

- Precipitation

The mean change of precipitation projected by the Eta-HadGEM and Eta-MIROC5 simulations, for the three timeslices: 2011-2040, 2041-2070, and 2071-2100, and for the two emission scenarios: RCP 4.5 and RCP 8.5 are shown in Figure 4 for austral summer, DJF, and in Figure 5 for austral winter, JJA. Similar to the temperatures, composites of the upper and lower ranges of the precipitation changes among the four projections are included in the two rightmost columns. In DJF, the major reduction of precipitation is found in a large area that extends from NO region to CS region, an area generally occupied by the South Atlantic Convergence Zone (SACZ); this is the main meteorological system that accumulates large amounts of precipitation in summer in the continent. The change suggests the reduction in the frequency of occurrence of SACZ or reduction in the activity of the SACZ in producing precipitation. This reduction is in agreement with the intensification of the subtropical high pressure and winds over the continent, which may block the passage of cold fronts moving toward the lower latitudes. In comparison with previous Eta-HadCM3 A1B projections [4], this area of reduction of precipitation has expanded farther southward reaching the region south of Brazil. Although, this sign of reduction of precipitation occurs in all four nested simulations, in both emission scenarios of the Eta-HadGEM simulations, this reduction intensifies toward the end of the century. In these simulations, the region of maximum reduction of precipitation is positioned in central and part of Southeast of Brazil, not as much in the Amazon or Northeast of Brazil as in [4]. In summer, the northern part of Northeast of Brazil displays increase in precipitation in both RCP scenarios of the Eta-MIROC5 and in RCP 4.5 of the Eta-HadGEM simulations, whereas only the Eta-HadGEM RCP 8.5 shows reduction of precipitation in all Northeast of Brazil. The precipitation regime in the northern part of Northeast Brazil is generally dependent on the position of the Intertropical Convergence Zone (ITCZ). In Eta-MIROC5 simulations, the precipitation band associate with ITCZ displaces southward causing increase in precipitation in the northern part of the Northeast of Brazil region, whereas in the Eta-Had- GEM no clear displacement occurs, but overall precipitation reduction in the band. The reduction of precipitation in southern Chile in all future timeslices is a feature shared in these simulations. 


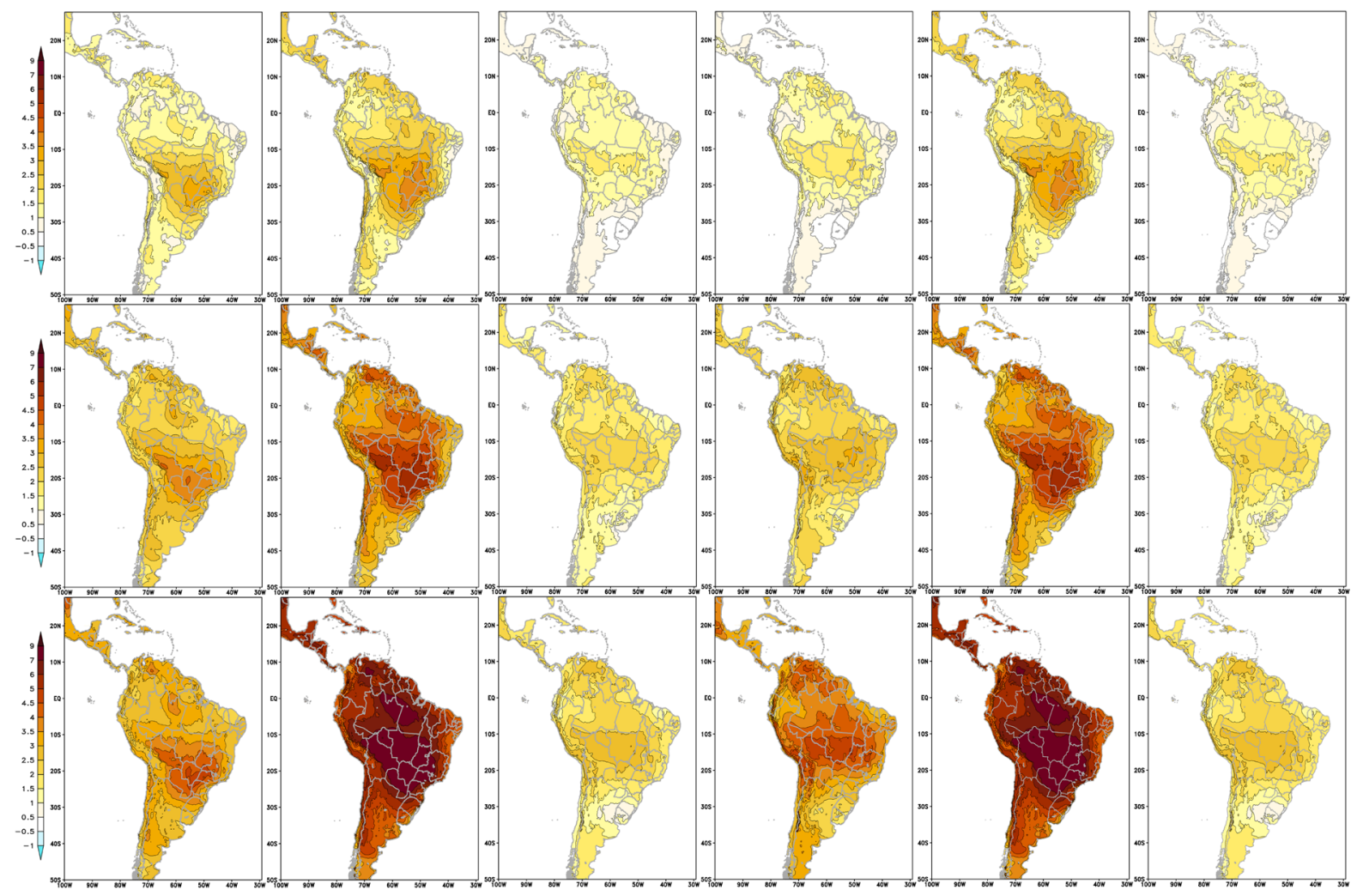

Figure 2. Difference of DJF mean 2-m temperature $\left({ }^{\circ} \mathrm{C}\right)$, between future and present (1961-1990) periods. Columns from left to right: 1-RCP 4.5 Eta-HadGEM; 2-RCP 8.5 Eta-HadGEM; 3-RCP 4.5 Eta-MIROC5; 4-RCP 8.5 Eta-MIROC5; 5-Composite of upper range of the changes; and 6 - composite of lower range of the changes. Future periods are 2011-2040 (top row), 2041-2070 (middle row), and 2071-2100 (bottom row).

In winter, in JJA, with the migration of ITCZ band toward northern latitudes (Figure 5), the reduction in precipitation occurs in the northern part of the continent, and it extends over Central America and Caribbean region. While in the eastern Pacific, the precipitation band associated with the ITCZ is displaced southward in all simulations, in the Atlantic, the band has moved away from the coast and causes a reduction in the precipitation along the eastern coast of Northeast Brazil. In addition, in JJA, precipitation is projected to increase in southeast South America, but limited to areas near the coastal, and is projected to reduce in southern Chile.

\subsection{Annual Cycle}

- 2-m temperature

The annual cycle of temperature is shown for RCP 4.5 (Figures 6(a)-(c)) and RCP 8.5 (Figures 6(d)-(f)) for three regions in Brazil: NO, NE and CS. The present climate simulation is also plotted for comparison of the changes. Despite some lags of phase of 1 month between the Eta-HadGEM and Eta-MIROC5, the amplitude of the annual cyclesis approximately maintained along the year in each timeslice. Therefore, the increase in temperature from the present to the each future timeslice is kept about the same magnitude along the year, but with small increase in the amplitude of the temperature cycle in the months around October and November. Larger warming occurs in RCP8.5 as expected in higher equivalent $\mathrm{CO}_{2}$ concentrations. The Eta-HadGEM produces warming values larger than Eta-MIROC5 in all three regions and periods. Larger warming is found in NO region, in RCP 8.5, which can reach about $8^{\circ} \mathrm{C}$ on average, whereas the smallest warming is found in NE region in RCP 4.5 with warming of about $1.5^{\circ} \mathrm{C}$. In RCP 4.5 , the largest changes in temperature occur between the present and the first period, 2011-2040, whereas in the RCP 8.5 the largest warming occurs between 2041-2070 and 2071-2100. No clear change of phase of the annual cycle is suggested in the projections of temperature for these regions.

- Precipitation 


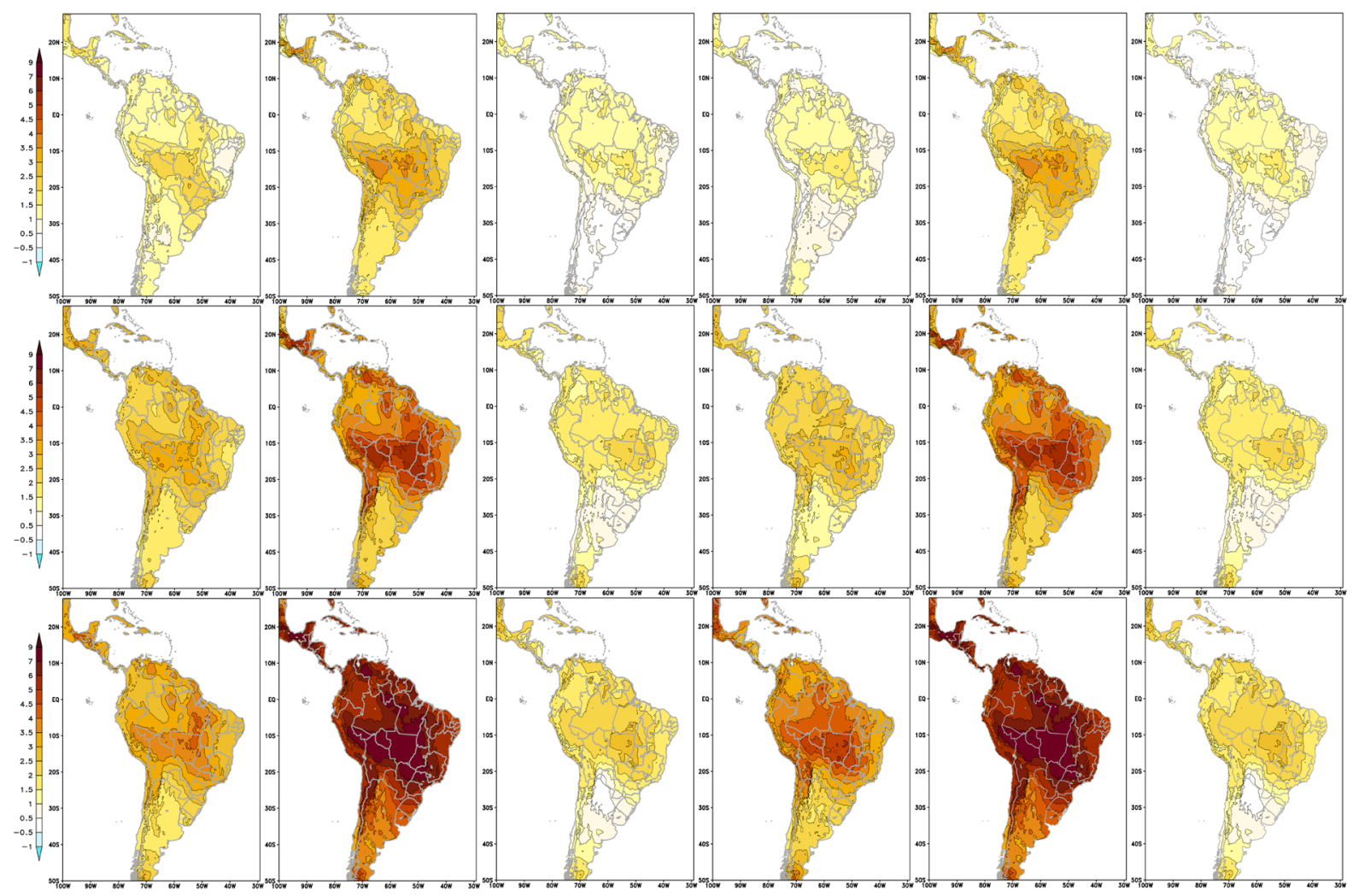

Figure 3. Difference of JJA mean 2-m temperature $\left({ }^{\circ} \mathrm{C}\right)$, between future and present (1961-1990) periods. Columns from left to right: 1-RCP 4.5 Eta-HadGEM; 2-RCP 8.5 Eta-HadGEM; 3-RCP 4.5 Eta-MIROC5; 4-RCP 8.5 Eta-MIROC5; 5-Composite of upper range of the changes; and 6-composite of lower range of the changes. Future periods are 2011-2040 (top row), 2041-2070 (middle row), and 2071-2100 (bottom row).

The annual cycle of precipitation shows that the Eta simulations driven by MIROC5 produces more precipitation than the Eta driven by HadGEM2-ES during the rainy season, and generally less during the dry season, therefore the Eta-MIROC5 exhibits a larger amplitude of the annual cycle of precipitation for both RCPs in all three regions (Figure 7). Precipitation reduction is generally found in all months and in all regions, except in the CS region, during the transition season of September-October-November (SON), when the Eta-HadGEM reduces precipitation, the Eta-MIROC5 increases the precipitation respect to present climate (Figures 7(e)-(f)). In addition, the Eta-HadGEM simulations show an increase of precipitation during dry season (JJA) in CS region, which modifies the annual cycle. Most of this modification is caused by the increase of precipitation in southern part of Brazil. These mixed signals of precipitation change in the CS region reveal large uncertainty in the assessment. Despite the increase of precipitation shown in the northern part of the NE region (Figure 4) during the DJF, the projected annual cycle shows that the reduction of precipitation dominates in the region in all months. Both Eta-HadGEM and Eta-MIROC5 simulations in RCP 8.5 scenario suggest extending the length of the dry season in NE.

\subsection{Time Series}

The time series of 2-m temperature simulated by the Eta-HadGEM and Eta-MIROC5, from 1961 until 2100, for DJF and JJA, and mean over the three regions (NO, NE and CS) are shown in Figure 8. Both Eta-HadGEM and Eta-MIROC5 simulations underestimate temperatures in the present climate, but the Eta-HadGEM is closer to the observations in both summer and in winter seasons. Despite the differences in the individual model biases, in the future, the four simulations exhibit warming trends in the three regions. In addition, toward the end of the $21^{\text {st }}$ century, the Eta-HadGEM simulations in RCP 8.5 scenario show more sensitivity to the increase of $\mathrm{CO}_{2}$ as the temperature curve exhibits higher rate of warming with respect to RCP 4.5 than the Eta-MIROC5 RCP 8.5 warming with respect to its RCP 4.5 simulation. The interannual variability of DJF temperature in NO and NE 


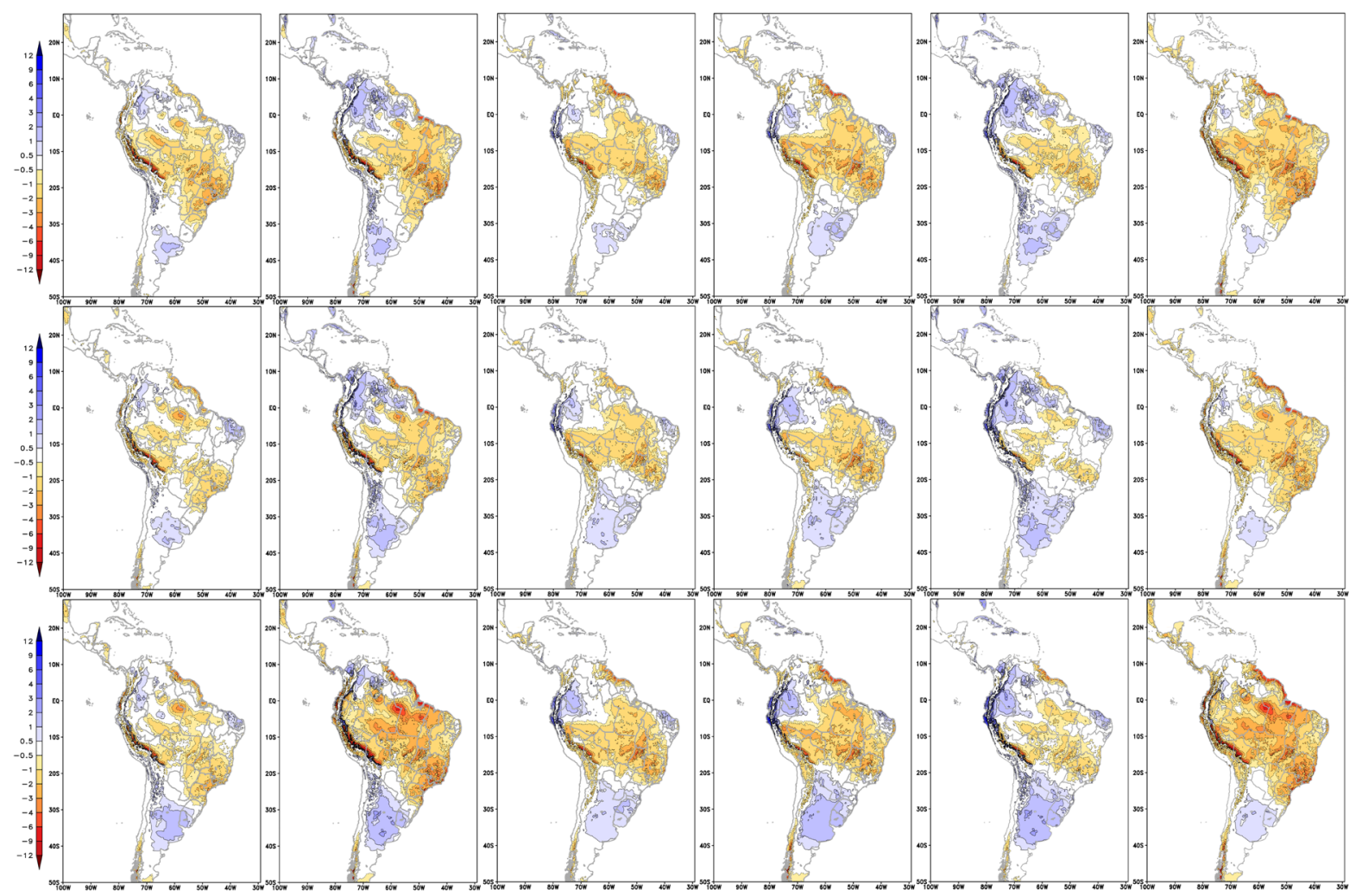

Figure 4. Difference of DJF mean precipitation (mm/day), between future and present (1961-1990) periods. Columns from left to right: 1-RCP 4.5 Eta-HadGEM; 2-RCP 8.5 Eta-HadGEM; 3-RCP 4.5 Eta-MIROC5; 4-RCP 8.5 Eta-MIROC5; 5-Composite of maximum changes; and 6-composite of minimum changes. Future periods are 2011-2040 (top row), 2041-2070 (middle row), and 2071-2100 (bottom row).

regions is larger in Eta-MIROC5 than in the Eta-HadGEM simulations. Clearly, the interannual variability of temperature increases in the future.

The time series of precipitation, for the two emission scenarios, in DJF and JJA, are shown in Figure 9. In general, for precipitation, the Eta-MIROC5 simulation is closer to observations than the Eta-HadGEM for the present climate period. The simulations from Eta-HadGEM underestimate precipitation in all three regions and in both seasons. In the future, there is no clear trend in the area averaged precipitation, in some periods the curve exhibits increase and in other periods decrease. During summer, in DJF, the time series show trend for reduction of precipitation in all regions in both emission scenarios, RCP 8.5 and RCP 4.5. During winter, the simulations show agreement with a small increase of precipitation in CS region and a small reduction in the NO region.

\subsection{Frequency Distribution}

The frequency distributions of daily mean temperatures for the three regions are shown in Figure 10. The frequency is plotted in logarithmic axis in order to make visible the extreme values of the distribution. The historical timeslice refers to the 1961-1990 period. The narrow distribution in NO and NE reflects the smaller variability of the tropical region, whereas the broader distribution in CS reveals the larger variability of the subtropics. The displacement of the peaks at the most frequent daily temperatures toward higher values by about $3^{\circ} \mathrm{C}$ in the RCP 4.5, and about $6^{\circ} \mathrm{C}$ in the RCP 8.5, occurs in all three regions. The distribution curves follow this displacement, except in NE that includes colder daily temperature events at the last timeslice. The distribution of the Eta-HadGEM reaches higher temperature values than the Eta-MIROC5 at the last timeslice, between 20712100.

The frequency distributions of daily-accumulated precipitation for the three regions are shown in Figure 11. The linear-log axis is also applied to the precipitation distribution curves to help stand out the heavier precipitation rates which are much less frequent than weak precipitation rates. The frequency distribution of Eta- 


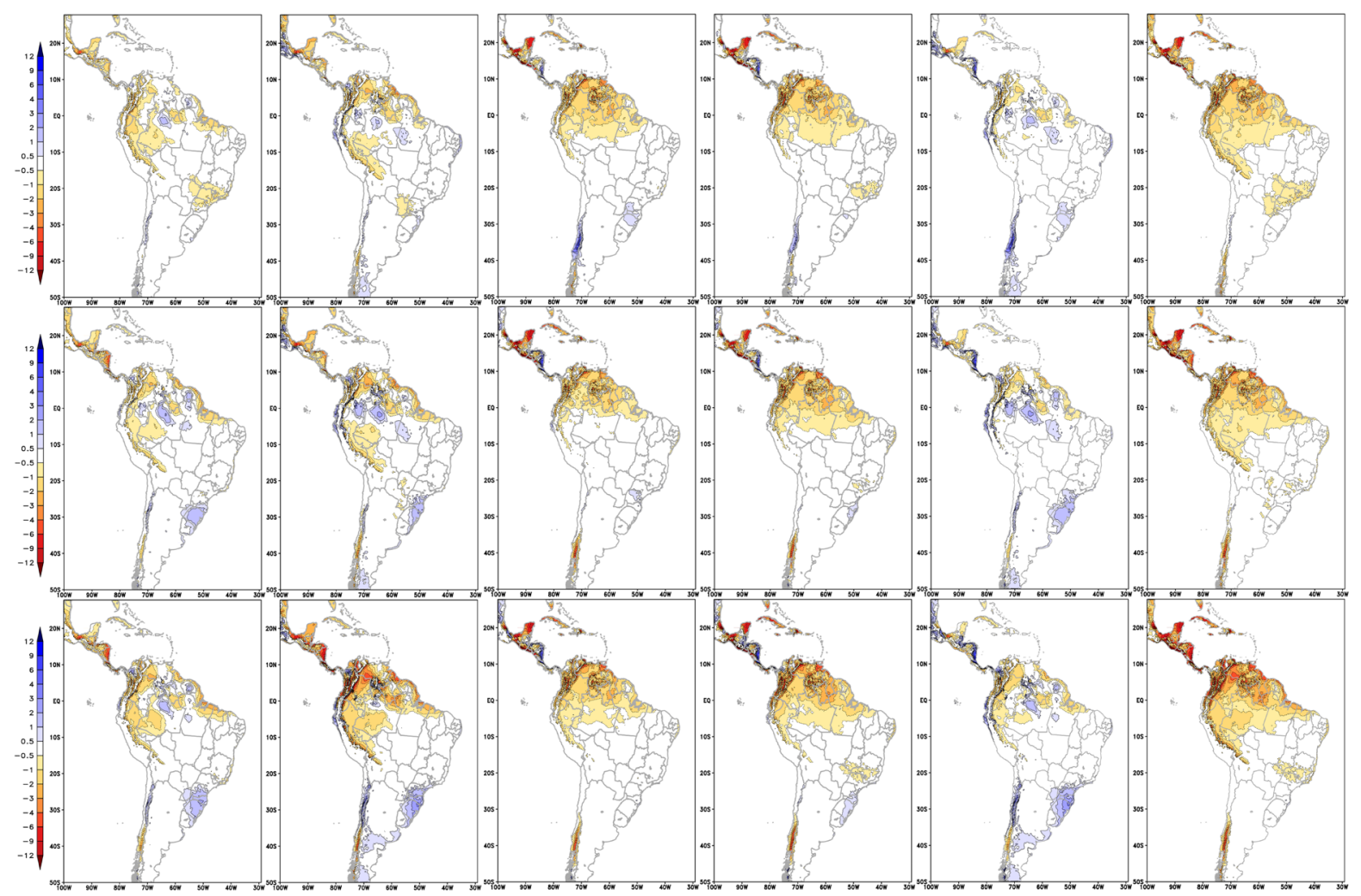

Figure 5. Difference of JJA mean precipitation (mm/day), between future and present (1961-1990) periods. Columns from left to right: 1-RCP 4.5 Eta-HadGEM; 2-RCP 8.5 Eta-HadGEM; 3-RCP 4.5 Eta-MIROC5; 4-RCP 8.5 Eta-MIROC5; 5-Composite of maximum changes; and 6-composite of minimum changes. Future periods are 2011-2040 (top row), 2041-2070 (middle row), and 2071-2100 (bottom row).

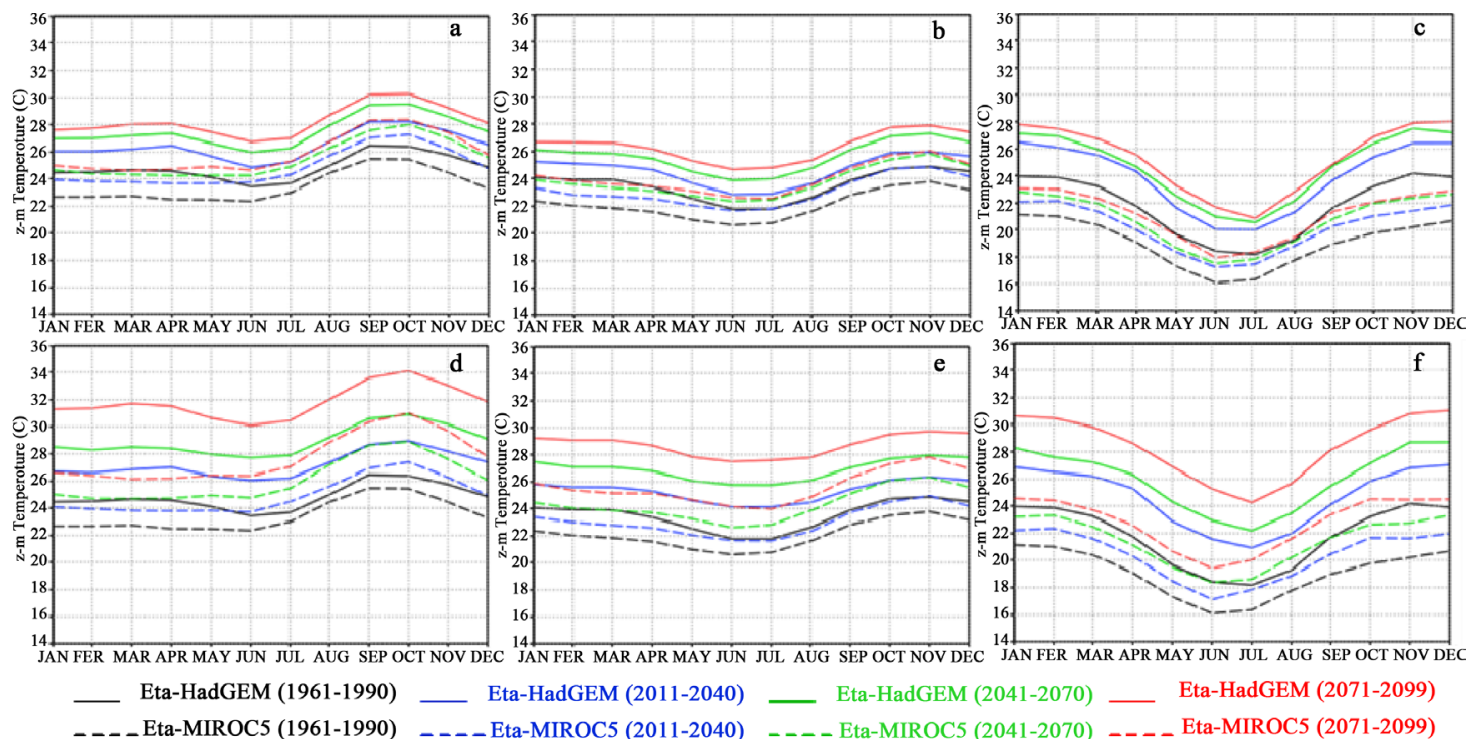

Figure 6. Mean annual cycle of 2-m temperature $\left({ }^{\circ} \mathrm{C}\right)$ simulated by the Eta model for four timeslices: 1961-1990 (historical), 2011-2040, 2041-2070, 2071-2100, for RCP 4.5 (top row) and RCP 8.5 (bottom row), and for the three regions: NO (left), NE (middle), and CS (right).

MIROC5 simulations produce more events of heavier precipitation than the Eta-HadGEM. In the RCP 4.5, little impact is noticed on the frequency distribution of Eta-HadGEM precipitation rates in the tropical regions of 

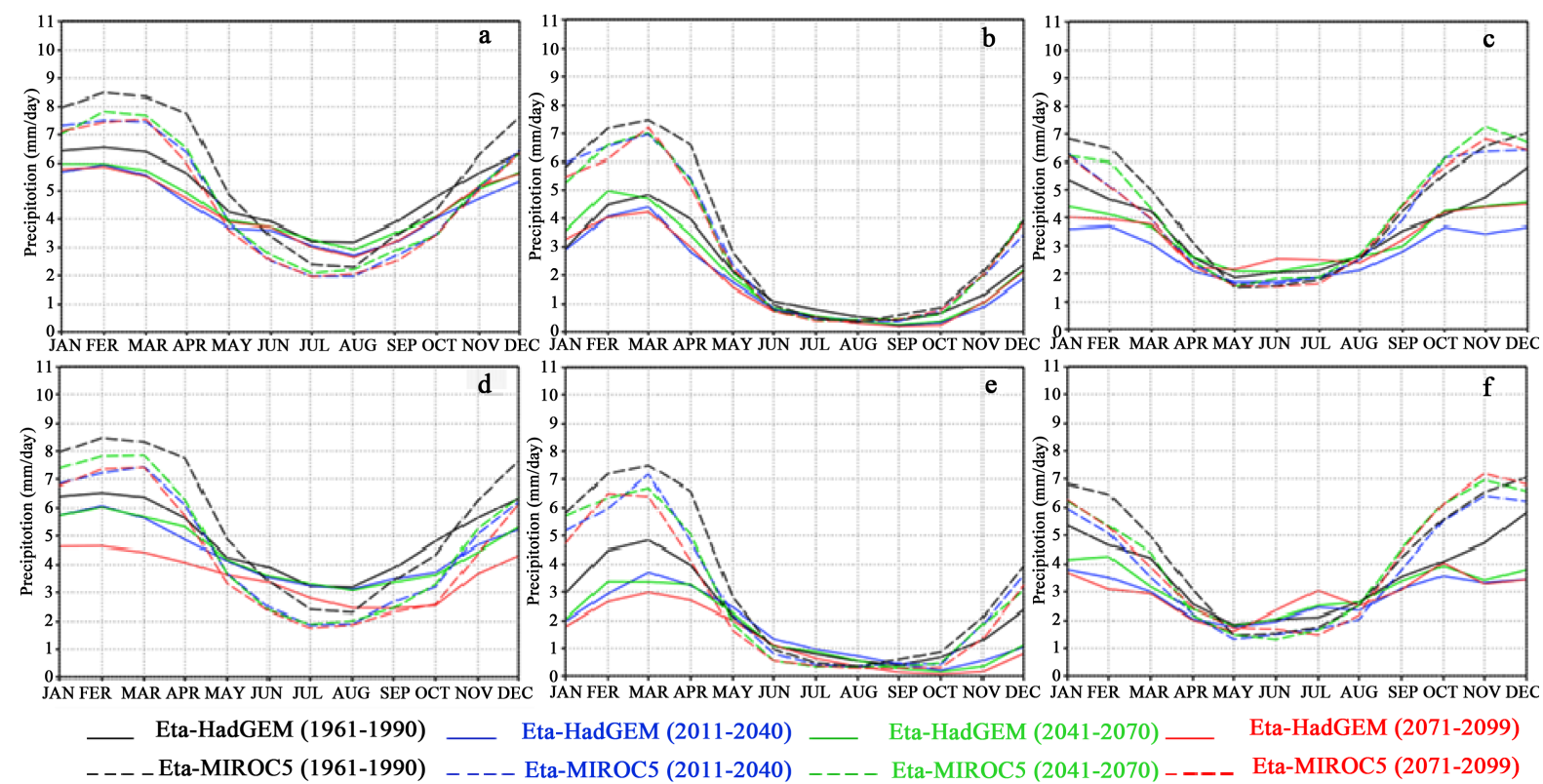

Figure 7. Mean annual cycle of precipitation (mm/day) simulated by the Eta model for four timeslices 1961-1990 (historical), 2011-2040, 2041-2070, 2071-2100, for RCP 4.5 (top row) and RCP 8.5 (bottom row), for the three regions: NO (left), NE (middle), and CS (right).

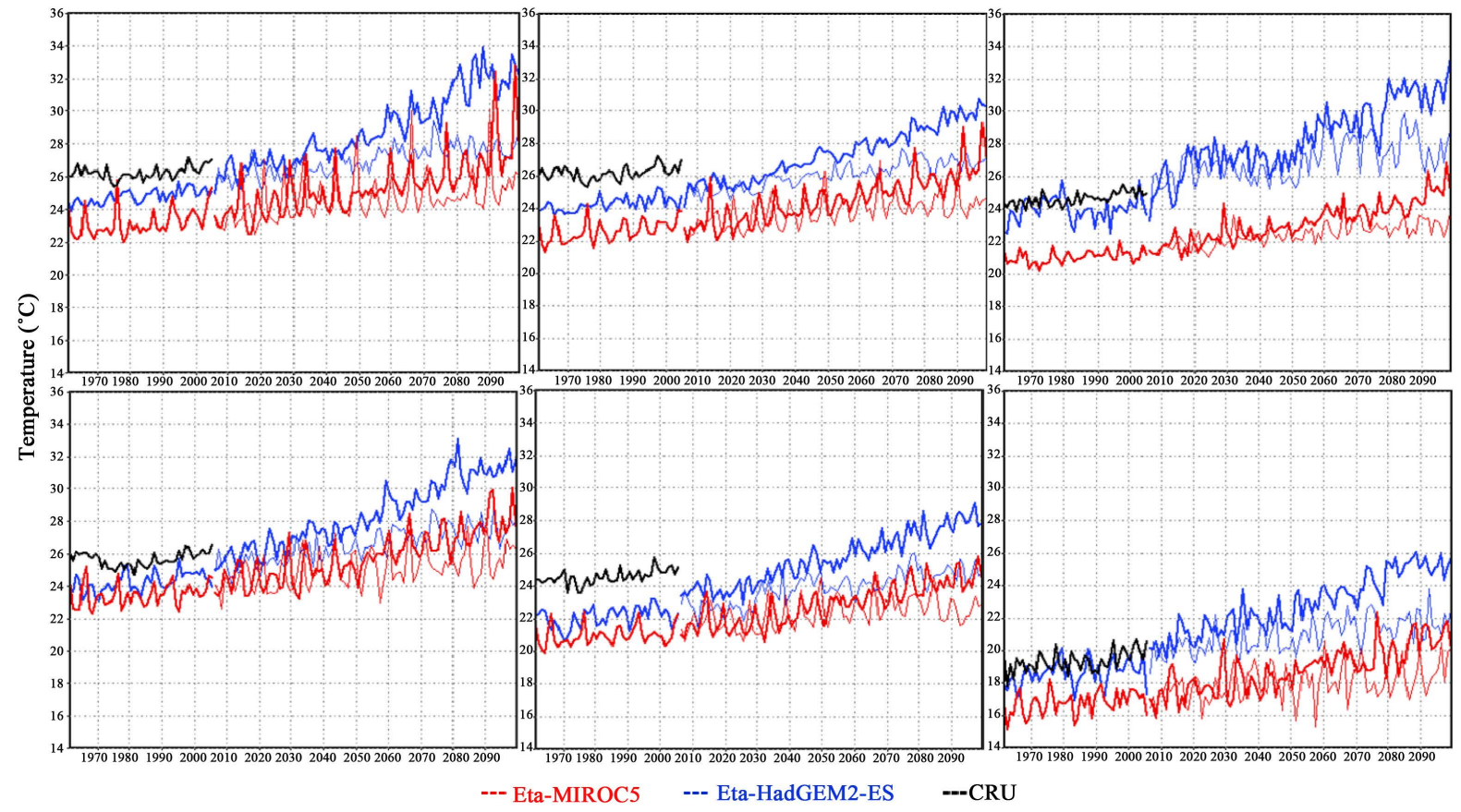

Figure 8. Mean temperature $\left({ }^{\circ} \mathrm{C}\right.$ ) yearly from 1961 until 2100, for RCP 4.5 (thin lines) and RCP 8.5 (thick lines) for DJF (top row) and JJA (bottom row) in NO (left), NE (middle), and CS (right column) regions.

NO and NE, but in the subtropical CS region, the Eta-HadGEM simulations exhibit more precipitation impacts with increase of frequency of heavy rains toward the end of the century. In the RCP8.5, the changes in the frequency distribution of precipitation rates are much more evident in all three regions. Heavier precipitation rates are attained in the first and middle timeslices, 2011-2040 and 2041-2070, in NE and CS regions. Despite the general predominant reduction of precipitation in the three regions shown during the rainy season, heavy precipitation events become more frequent in the future timeslices. 


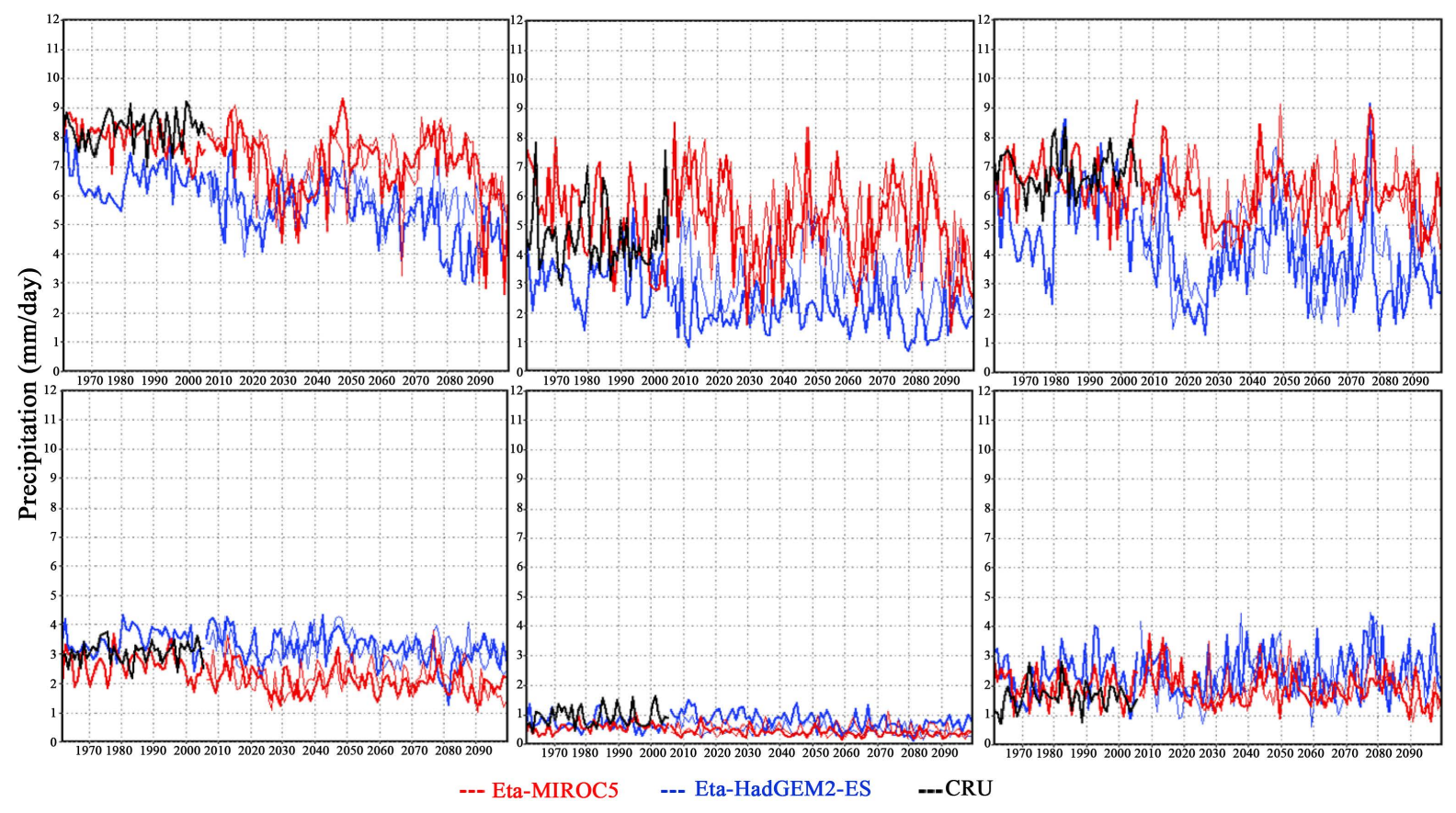

Figure 9. Mean precipitation (mm/day) yearly from 1961 until 2100, for RCP 4.5 (thin lines) and RCP 8.5 (thick lines) for DJF (top row) and JJA (bottom row) in NO (left), NE (middle), and CS (right column) regions.
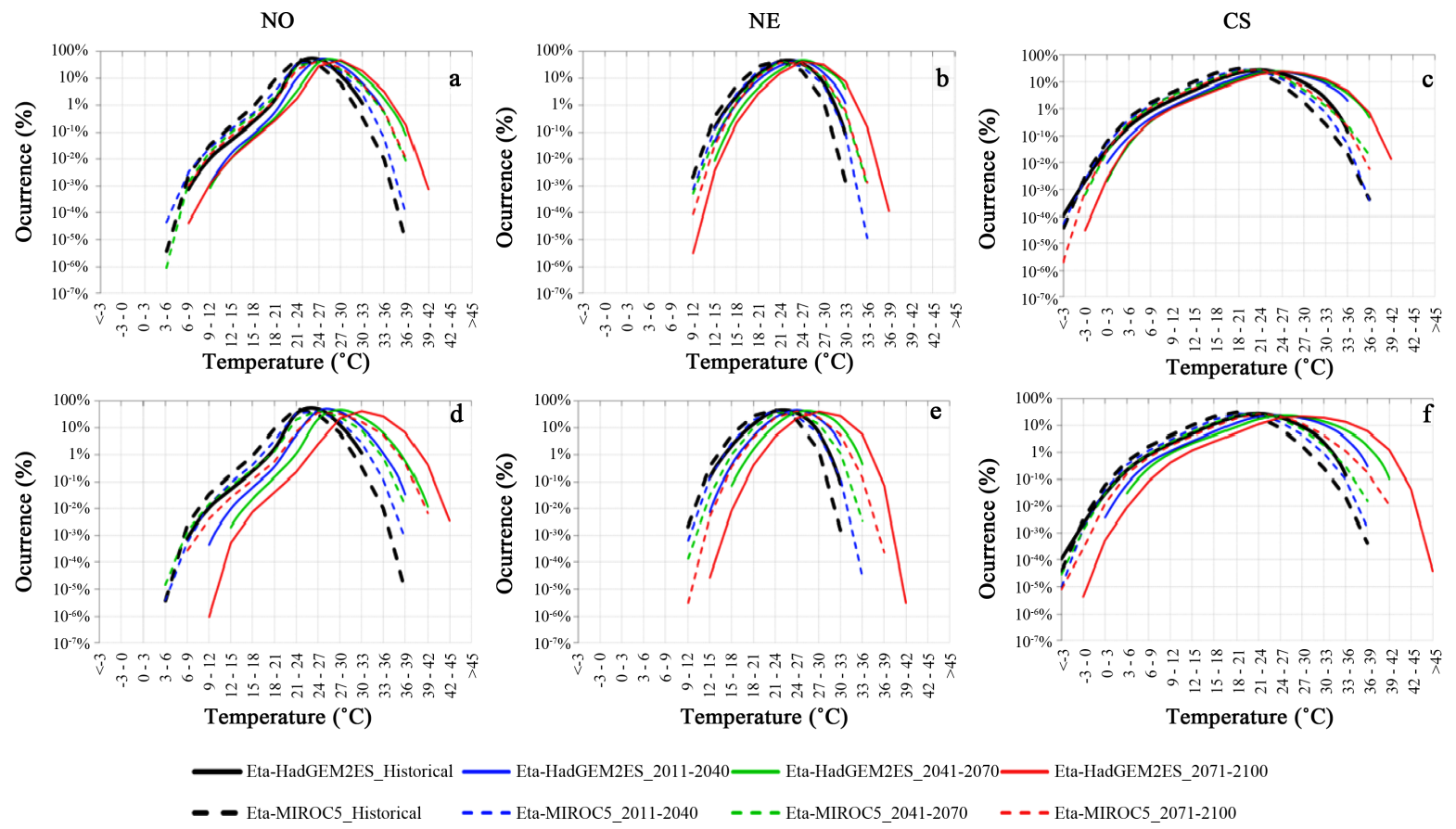

Figure 10. Frequency distribution (\%) of daily mean temperature $\left({ }^{\circ} \mathrm{C}\right.$ ), for RCP 4.5 (top row) and RCP 8.5 (bottom row), for NO (left), NE (middle), and CS (right column) regions.

\subsection{Climatic Extreme Indicators}

Four climatic extreme indicators based on daily precipitation are calculated for the downscaling projections: the total annual precipitation (PRCPTOT), the amount of precipitation from days that exceeded the $95^{\text {th }}$ percentile of daily precipitation (R95p), the annual maximum consecutive dry days (CDD), and the annual maximum consec- 

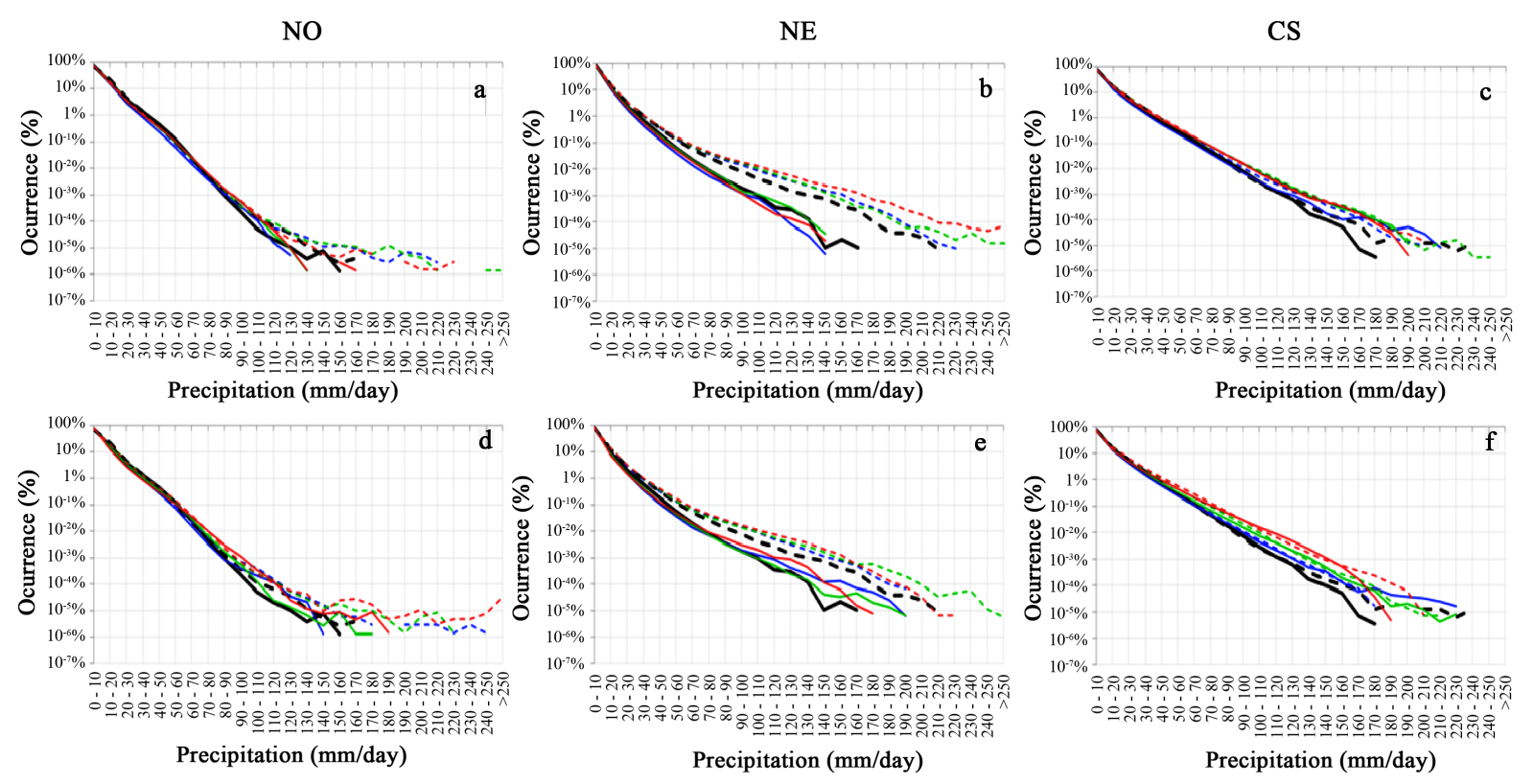

—Eta-HadGEM2ES_Historical ——Eta-HadGEM2ES_2011-2040—_Eta-HadGEM2ES_2041-2070—— Eta-HadGEM2ES_2071-2100

- Eta-MIROC5_Historical - - - Eta-MIROC5_2011-2040 - - - Eta-MIROC5_2041-2070 - - - Eta-MIROC5_2071-2100

Figure 11. Frequency distribution (\%) of daily precipitation (mm/day), for RCP 4.5 (top row) and RCP 8.5 (bottom row), for NO (left), NE (middle) and CS (right column) regions.

utive wet days (CWD). These indicators can suggest the changes in the characteristics of the total daily precipitation. Differences between the mean indicator at each future timeslice and mean indicator in the present climate timeslice (1961-1990) are shown in Figure 12, for the upper range and the lower range of changes among the four simulations of the climatic indicators, for the three future timeslices. In the figures, the patterns in red indicate drier conditions and in blue, wetter conditions.

The composite of the lower range of the change of PRCPTOT indicator shows a decrease in annual rainfall during the $21^{\text {st }}$ century in most of the Amazon region and Southeast of Brazil. In those regions, the total annual precipitation can reduce in about $700 \mathrm{~mm}$, with respect to the present climate by the end of the century. An increase in the total annual rainfall (blue areas) occurs over the southern part of South America and reaches anincrease over $500 \mathrm{~mm}$ by the end of the century. This result agrees with [18] using RCP 4.5 scenario, where the $50^{\text {th }}$ percentile of the model ensemble projects a drier climate in the NO and NE regions of Brazil and a wetter climate in the southeastern South America (SESA) in the future. The increase of PRCPTOT in the northern part of $\mathrm{NE}$ is also shown in these projections.

The change of heavy precipitation (R95p) indicator shows a small reduction in the amount of extreme precipitation rates over part of the Amazon, in central and Southeast of Brazil in all three timeslices. This reduction in the accumulated precipitation events is due to the increase toward the end of the century of the value of the $95^{\text {th }}$ percentile of the daily precipitation rate. On the other hand, the increase of R95p indicator with respect to present climate occurs over SESA. The change grows larger toward the end of the $21^{\text {st }}$ century. These changes of a drier climate in the North and Northeast of Brazil and a wetter climate in SESA are similar to the changes found by [19] using AR4 scenarios.

The composite of the upper range of changes of CDD indicator highlights an increase of consecutive dry days mainly over the Northeast of Brazil, where a semi-arid area is already present. This drier condition intensifies toward the end of the century. This region is also identified as a hotspot region in terms of water resources [20]. This result is in agreement with [19] [21]. Decrease in CDD is considered in the lower range composites, and the areas of decreasing CDDs are found in the central Argentina in the frontogenetical region, and in all three timeslices. The change in the CWD indicator shows a decrease of the consecutive wet days with respect to the present climate. This change is projected mainly in the Amazon region. Positive changes of CWD hardly occurs in the continent, not even in SESA were a wetter climate is projected. 


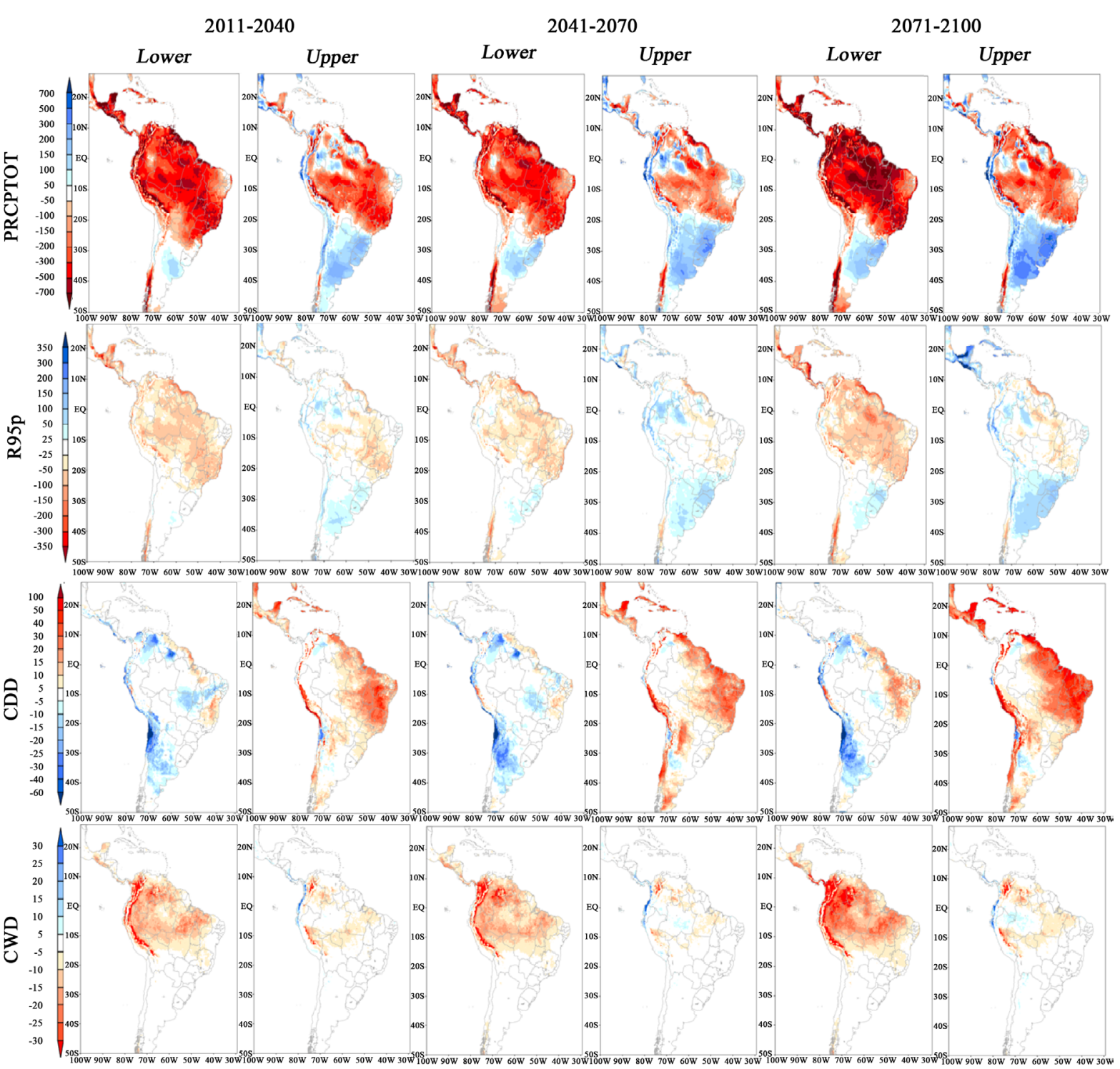

Figure 12. Lower and Upper ranges of change of the climatic extreme indicators: PRCPTOT (mm), R95p (mm), CDD (days), and CWD (days) in three timeslices.

\section{Conclusions}

The Eta RCM is applied to generate four downscaling simulations of climate change. Two GCMs, the HadGEM2-ES and the MIROC5, and two AR5 IPCC scenarios, RCP 4.5 and RCP 8.5, force the simulations. The objective of this work is to assess the climate change over South America reproduced by these downscaling simulations.

Warming is projected in the entire continent, with larger amplitude in the Eta forced by HadGEM2-ES RCP 8.5 scenario. The warming starts in the central and southeastern Brazil and progresses strongly toward the northern part of the continent. Major change in precipitation is the reduction in Southeast of Brazil. Both Eta simulations driven by HadGEM2-ES and Eta driven by MIROC5 intensify the reduction of precipitation toward the end of the century. The region between the South and Southeast of Brazil exhibits the most mixed signs of precipitation changes. The northern part of Northeast of Brazil shows positive precipitation change with respect to 1961-1990 period in three simulations, but negative change in the RCP 8.5 Eta-HadGEM scenario. The frequency distributions of temperature and precipitation show the inclusion of extreme higher values as the timeslices advance toward the end of the $21^{\text {st }}$ century. Events of extreme heavy rainfall become more frequent in the sou- 
theastern South America area and a reduction of heavy rainfall rate is found in the area of annual total precipitation reduction.

These simulations attempt to contribute to the assessment of impacts of climate change in different economic sectors. Generally, socio-economic impacts have local or regional scale, which makes the downscaling technique appropriate for the studies. The pessimistic and optimistic RCP scenarios and the use of two global models producing nested simulations of different error behaviors, attempt to include more possibilities and uncertainties in the assessment of the impacts of climate change. Previous impact studies over the region were based on the downscaling of climate change simulated from the same family of global models, HadAM3 and HadCM3 [3] [4]. In this work, a different architecture of global model is included, the MIROC5, and tries to considerer additional possibilities to the climate change impacts at local scale. Downscaling simulations by considering other global model simulations and further investigation to understand the simulated climate changes are planned.

\section{Acknowledgements}

The authors thank: the Brazilian Ministry of Science, Technology, and Innovation for supporting the work through Global Environmental Facility funding (UNDP BRA/10/G32), the Secretariat for Strategic Affairs of the presidency of Brazil for additional funding, Martin Juckes from the British Atmospheric Data Centre for making available HadGEM2-ES dataset, and Seita Emori and Tokuta Yokohata from the Japanese National Institute for Environmental Studies for making available the MIROC5 dataset. Sin Chan Chou thanks the Brazilian National Council for Scientific and Technological Development (CNPq) for the grants 308035/2013-5 and 400792/ 2012-5.

\section{References}

[1] IPCC (2000) IPCC Special Report on Emissions Scenarios. Prepared by Working Group III of the Intergovernmental Panel on Climate Change. Cambridge University Press, United Kingdom and New York, 377.

[2] Nakicenovic, N., et al. (2000) Special Report on Emissions Scenarios: A Special Report of Working Group III of the Intergovernmental Panel on Climate Change. Cambridge University Press, Cambridge, 599.

[3] Krüger, L.F., da Rocha, R.P., Reboita, M.S. and Ambrizzi, T. (2012) RegCM3 Nested in HadAM3 Scenarios A2 and B2: Projected Changes in Extratropical Cyclogenesis, Temperature and Precipitation over the South Atlantic Ocean. Climatic Change, 113, 599-621.

[4] Marengo, J.A., et al. (2012) Development of Regional Future Climate Change Scenarios in South America Using the Eta CPTEC/HadCM3 Climate Change Projections: Climatology and Regional Analyses for the Amazon, São Francisco and the Parana River Basins. Climate Dynamics, 38, 1829-1848. http://dx.doi.org/10.1007/s00382-011-1155-5

[5] Chou, S.C., et al. (2012) Downscaling of South America Present Climate Driven by 4-Member HadCM3 Runs. Climate Dynamics, 38, 635-653. http://dx.doi.org/10.1007/s00382-011-1002-8

[6] Pesquero, J.F., Chou, S.C., Nobre, C.A. and Marengo, J.A. (2010) Climate Downscaling over South America for 19611970 Using the Eta Model. Theoretical and Applied Climatology, 99, 75-93. http://dx.doi.org/10.1007/s00704-009-0123-z

[7] Flato, G., Marotzke, J., Abiodun, B., Braconnot, P., Chou, S.C., Collins, W., Cox, P., Driouech, F., Emori, S., Eyring, V., Forest, C., Gleckler, P., Guilyardi, E., Jakob, C., Kattsov, V., Reason, C., and Rummukainen, M. (2013) Evaluation of Climate Models. In: Climate Change 2013: The Physical Science Basis. Contribution of Working Group I to the Fifth Assessment Report of the Intergovernmental Panel on Climate Change. Stocker, T.F., Qin, D., Plattner, G.-K., Tignor, M., Allen, S.K., Boschung, J., Nauels, A., Xia, Y., Bex, V. and Midgley, P.M., Eds., Cambridge University Press, Cambridge, United Kingdom and New York, 9, 741-866. http://dx.doi.org/10.1017/CBO9781107415324.020

[8] Chou, S.C., Lyra, A., Mourão, C., Dereczynski, C., Pilotto, I., Gomes, J., Bustamante, J., Tavares, P., et al. (2014) Evaluation of the Eta simulations Nested in Three Global Climate Models. American Journal of Climate Change. (In Press)

[9] IPCC (2007) Climate Change 2007: The Physical Science Basis. Contribution of Working Group I to the Fourth Assessment Report of the Intergovernmental Panel on Climate Change. Solomon, S., Qin, D., Manning, M., Chen, Z., Marquis, M., Averyt, K.B., Tignor, M. and Miller, H.L., Eds, Cambridge University Press, Cambridge, United Kingdom and New York, 996.

[10] IPCC (2013) Climate Change 2013: The Physical Science Basis. Contribution of Working Group I to the Fifth Assessment Report of the Intergovernmental Panel on Climate Change. Stocker, T.F., Qin, D., Plattner, G.-K., Tignor, M., Allen, S.K., Boschung, J., Nauels, A., Xia, Y., Bex, V. and Midgley, P.M. Eds., Cambridge University Press, Cambridge, United Kingdom and New York, NY, USA, 1535. http://dx.doi.org/10.1017/CBO9781107415324 
[11] Collins, W.J., et al. (2011) Development and Evaluation of an Earth-System Model—HadGEM2. Geoscientific Model Development, 4, 1051-1075, http://dx.doi.org/10.5194/gmd-4-1051-2011

[12] Martin, G.M., et al. (2011) The HadGEM2 Family of Met Office Unified Model Climate Configurations. Geoscientific Model Development, 4, 723-757, http://dx.doi.org/10.5194/gmd-4-723-2011

[13] Watanabe, M., et al. (2010) Improved Climate Simulation by MIROC5: Mean States, Variability, and Climate Sensitivity. Journal of Climate, 23, 6312-6335. http://dx.doi.org/10.1175/2010JCLI3679.1

[14] Mesinger, F. (1984) A Blocking Technique for Representation of Mountains in Atmospheric Models. Rivista di Meteorologia Aeronautica, 44, 195-202.

[15] Mesinger, F., Chou, S.C., Gomes, J.L., et al. (2012) An Upgraded Version of the Eta Model. Meteorology and Atmospheric Physics, 116, 63-79. http://dx.doi.org/10.1007/s00703-012-0182-z

[16] Ek, M., et al. (2003) Implementation of Noah Land Surface Model Advances in the National Centers for Environmental Prediction Operational Mesoscale Eta Model. Journal of Geophysical Research, 108, 8851. http://dx.doi.org/10.1029/2002JD003296

[17] Satyamurty, P., Nobre, C.A. and Silva Dias, P.L. (1998) South America. In: Karoly, D.J. and Vincent, D.G., Eds., Meteorology of the Southern Hemisphere, American Meteorological Society, Boston, 119-139.

[18] IPCC (2013) Annex I: Atlas of Global and Regional Climate Projections. van Oldenborgh, G.J., Collins, M., Arblaster, J., Christensen, J.H., Marotzke, J., Power, S.B., Rummukainen, M. and Zhou, T., Eds., In: Climate Change 2013: The Physical Science Basis. Contribution of Working Group I to the Fifth Assessment Report of the Intergovernmental Panel on Climate Change. Stocker, T.F., Qin, D., Plattner, G.-K., Tignor, M., Allen, S.K., Boschung, J., Nauels, A., Xia, Y., Bex, V. and Midgley, P.M., Eds., Cambridge University Press, Cambridge, United Kingdom and New York, 1311-1394. http://dx.doi.org/10.1017/CBO9781107415324.029

[19] Marengo, J.A., Jones, R., Alves, L.M. and Valverde, M.C. (2009) Future Change of Temperature and Precipitation Extremes in South America as Derived from the PRECIS Regional Climate Modeling System. International Journal of Climatology, 29, 2241-2255. http://dx.doi.org/10.1002/joc.1863

[20] De Sherbinin, A. (2014) Climate Change Hotspots Mapping: What Have We Learned? Climatic Change, 123, $23-37$. http://dx.doi.org/10.1007/s10584-013-0900-7

[21] Tebaldi, C., Hayhoe, K., Arblaster, J. and Meehl, G. (2006) Going to the Extremes: An Intercomparison of Model-simulated Historical and Future Changes in Extreme Events. Climatic Change, 79, 185-211. http://10.1007/s10584-006-9051-4 
Scientific Research Publishing (SCIRP) is one of the largest Open Access journal publishers. It is currently publishing more than 200 open access, online, peer-reviewed journals covering a wide range of academic disciplines. SCIRP serves the worldwide academic communities and contributes to the progress and application of science with its publication.

Other selected journals from SCIRP are listed as below. Submit your manuscript to us via either submit@scirp.org or Online Submission Portal.
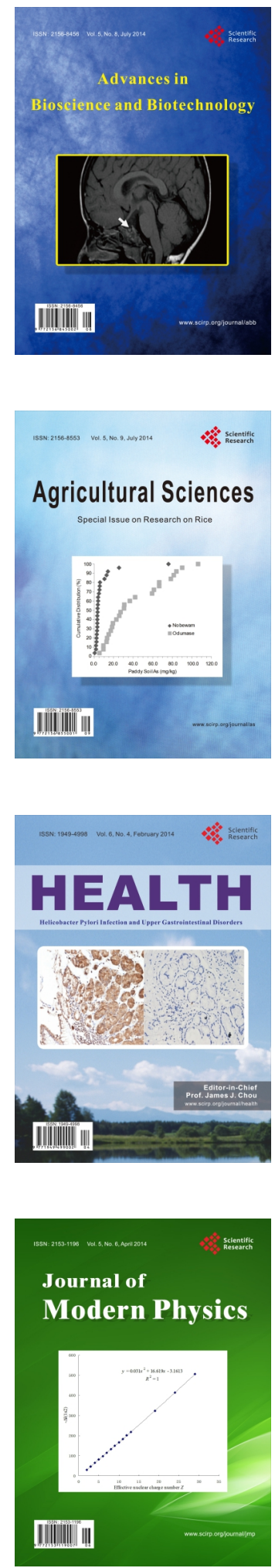
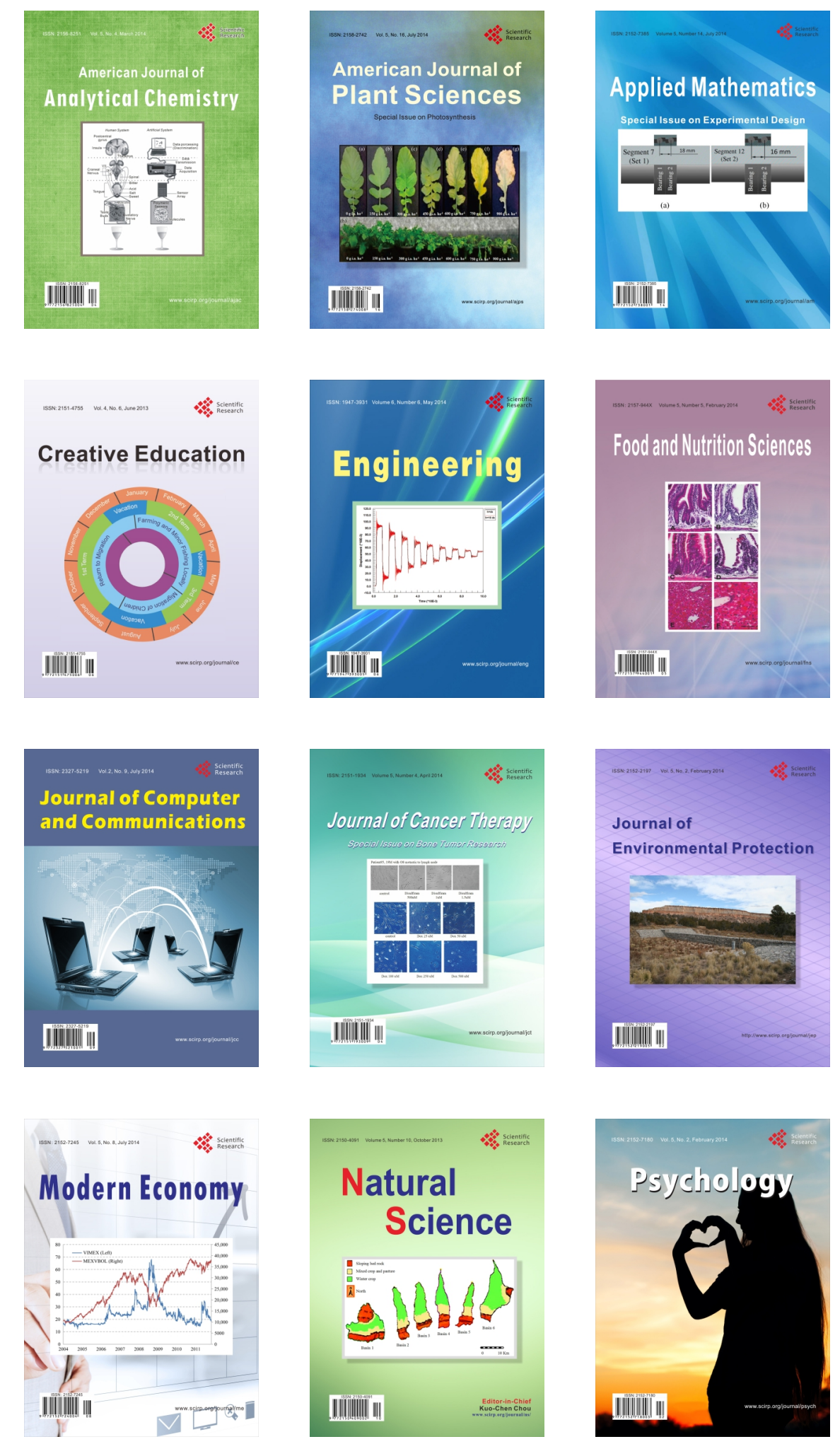